\title{
Stability Analysis on Factors of Jointed Rock Slopes
}

\author{
Ren Debin ${ }^{1, a}$, Dong Zheng ${ }^{2, b}$ Yang Xiaotong ${ }^{3, c}$ and Li Shipeng ${ }^{4, d}$
}

${ }^{1,2,3,4}$ No. 9, Shenyang Jianzhu University, Hunnan Road, Hunnan New District,Shenyang,Liaoning Province,China

a389706501@qq.com, b291115968@qq.com, '939709430@qq.com, d849996204@qq.com

Keywords: Finite element; Joint plane; Influence factors; Slopes; Strength reduction technique.

Abstract. The paper aims to research how the main parameters of the rock slopes with joint planes covered: Shear modulus, unit weight and the angles between the joint planes influence the stability and the failure modes of the slopes. The methods are to imitate the jointed rock slopes by the large-scale finite element simulation software, analyze and study the influences on the safety factors of slope and distribution or size of the equivalent plastic strain zones of above parameters with control variable method. The results show that: When the Shear modulus increase, the safety factors will also increase and the equivalent plastic strain zones will develop to the interior of the slope with obvious deformation. Unit weight of the rocks' increasing will make the safety factors decrease and the equivalent plastic strain zones develop to the crest and interior of the slopes with the area slightly increasing. The angles between the joint planes getting increased will make the safety factors decrease and the equivalent plastic strain zones develop to the interior of the slope with obvious deformation and the area decreasing. The examples show that: Shear modulus, unit weight and the angles between the joint planes have an important influence on the stability of jointed rock slopes

\section{Introduction}

The most rock slopes that we meet in the practical engineering contain weak structural surfaces such as joints, faults and cracks. It makes big difference in physical and mechanical properties in all directions ${ }^{[1]}$, and makes obvious distinctions in discontinuity, heterogeneous, anisotropic and inelastic, etc $^{[2]}$. In recent years, the studies of the weak structural surfaces get more attention in geotechnical engineering.

The slip mass is seen as the ideal rigid body when using traditional limit equilibrium method before. It is very difficult to find an accurate resolution ${ }^{[3]}$. In contrast, the strength reduction finite element method currently in use is more accurate and scientific. Its basic principles are using different reduction factor F orderly, constant changing strength parameters of the material under the formula(1) and turning it back into the finite element model for iterating and trialing during process of finite element analysis. By times of iterating and trialing, the "impending ultimate failure state" can be found, and the reduction factor $\mathrm{F}$ in that state is the safety factor.

\section{$c^{\prime}=c / F ; \quad \tan \emptyset^{\prime}=\tan \emptyset / F$}

From the theoretical analysis, the strength of the rock mass with joint planes is between the strength of rock and joint. Therefore, the stability of jointed rock slopes is common influenced by the strength of joint and rock. After strength reduction, the potential fracture of the rock mass may first appear in the masses, joint planes or both of them ${ }^{[4]}$. Its mainly depends on the mechanical state of rock mass, joint occurrence, mechanical state of joint and so on ${ }^{[5]}$. The author will use the large finite element analysis software ABAQUS, with strength subtraction technique to explore the influence of main mechanical and physical parameters to the stability and failure pattern of the slopes with joint planes.

\section{Joint model}

The author creates the joint material model to simulate the jointed rock mass by finite element analysis software ABAQUS. This model regards the rock mass as a material full of joints. The model 
assumes two groups of joint planes that cut through each other, intersect and both perpendicular to section of the slope. In the joint surface and its intersection area, the constitutive model adopts the joint model in ABAQUS, and uses the Mohr-Coulomb ideal elastoplastic model in other area.

The inclination angle on the joint plane is defined with Cartesian coordinates. The $\mathrm{x}, \mathrm{y}, \mathrm{z}$ are used in integral coordinate system, and x', y', z' are used in local coordinate system. The stress relational expression in the generalized coordinate system and local coordinate system is shown in type (2).

$$
\begin{aligned}
& \sigma^{\prime}=C^{T} \sigma C \\
& \text { where: } C=\left[\begin{array}{l}
\cos \left(x^{\prime}, x\right) \cos \left(x^{\prime}, y\right) \cos \left(x^{\prime}, z\right) \\
\cos \left(y^{\prime}, x\right) \cos \left(y^{\prime}, y\right) \cos \left(y^{\prime}, z\right) \\
\cos \left(z^{\prime}, x\right) \cos \left(z^{\prime}, y\right) \cos \left(z^{\prime}, z\right)
\end{array}\right]
\end{aligned}
$$

Basing on Mohr - Coulomb yield criterion, the yield envelope ABs expression in the local coordinate system is $\Gamma^{s}=0$; And tensile failure envelope $\mathrm{BCs}$ expression is $\Gamma^{\mathrm{t}}=0$, it also can be written as formula (3) ${ }^{[5]}$ :

$$
\left\{\begin{array}{l}
f^{s}=\tau+\sigma_{3}^{s} \tan \emptyset_{j}-c_{f} \\
f^{t}=\sigma_{3}^{t} \quad \sigma_{j}^{t} \\
f^{i}-\sigma_{3}^{s}-\sigma_{j}^{t}
\end{array}\right.
$$

where: $\emptyset_{j}, c_{j}, \sigma_{j}^{t}$ represent internal friction angle of joint, cohesion and tensile strength, respectively.

\section{Criterion of the instability of slope}

Selecting the criterion of the instability of slope is very important to elastic-plastic finite element strength reduction technique. At present, there are following four criterions that are approved by most of experts: (1) After the reduction of strength parameters, the finite element software can't convergence in specified number of iterations ${ }^{[9]}$.(2)The plastic zone runs through from upper slope to lower slope $\mathrm{e}^{[10]}$. (3) The generalized shear strain or equivalent plastic strain over a certain range forms through zone in a certain area. (4) The displacement of feature point on slope occur mutation. In this paper, the author will use the criterion (1) that it can't convergence in specified number of iterations, combined with the distribution of plastic zone and the magnitude of equivalent plastic strain to determine the stability of the slope.

\section{Analysis of examples}

\section{The influence of shear modulus to stability}

The study aims at the influence of shear modulus has important significance on the slope stability. Within the elastic working range, shear modulus is constant. But beyond the elastic range, shear modulus decreases along with the increase of stress. At present, the mainstream of the finite element analysis software and most of the scholars study are ignoring shear modulus changes beyond the elastic range and see it as a constant value of linear elastic. Therefore, author will also do the same with shear modulus in this paper. Rock slope containing two sets of intersecting joint planes, and the horizontal plane Angles are $52.5^{\circ}$ and $90^{\circ}$ respectively. Density of rock $\gamma=25 \mathrm{KN} / \mathrm{m}^{3}$, the cohesion of the rock $\mathrm{c}=$ $5600 \mathrm{KPa}$ with friction angle $\psi=45^{\circ}$, the cohesion of the structure is $3000 \mathrm{KPa}$ with friction angle $\varphi=45^{\circ}$, the shear modulus $\mathrm{G}$ take different values. The safety factors calculated by software are shown as table 1. 
Table 1 Shear modulus vs. Safety factors and Equivalent Strain amplitude

\begin{tabular}{lllllll}
\hline Shear modulus G[GPa] & 9.5 & 10 & 10.5 & 11 & 11.5 & 12 \\
\hline Safety factor & 1.004 & 1.032 & 1.040 & 1.046 & 1.049 & 1.057 \\
\hline $\begin{array}{l}\text { Equivalent Strain } \\
\text { Amplitude }\left[10^{-4}\right]\end{array}$ & 1.088 & 1.348 & 1.618 & 1.757 & 1.981 & 2.093 \\
\hline
\end{tabular}

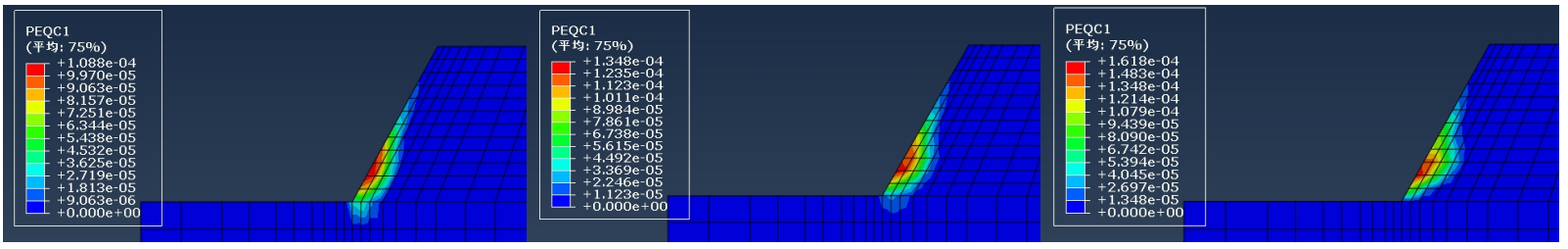

(a) $\mathrm{G}=9.5 \mathrm{GPa}$

(b) $\mathrm{G}=10 \mathrm{GPa}$

(c) $\mathrm{G}=10.5 \mathrm{GPa}$

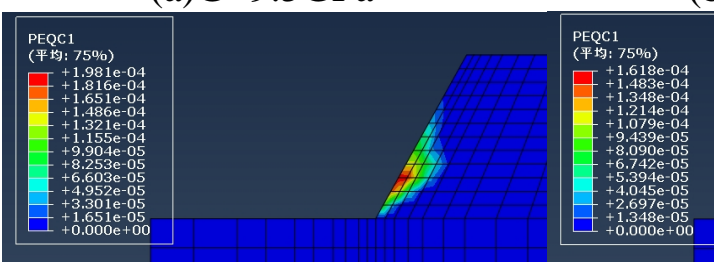

(d) $\mathrm{G}=11 \mathrm{GPa}$ (e) $\mathrm{G}=11.5 \mathrm{GPa}$
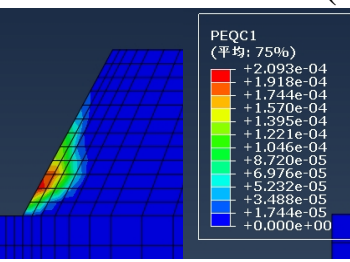

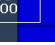

(f) $\mathrm{G}=12 \mathrm{GPa}$

Fig.1 nEquivalent plastic strain contours of angles between the joint planes

Conclusion: (1) From the table (1), the bigger the shear modulus of the slope is, the higher the safety factor is. When the shear modulus increases from $9.5 \mathrm{GPa}$ to $12 \mathrm{GPa}$ at $0.5 \mathrm{GPa}$ increase rate, the safety factor also increases gradually from 1.004 to 1.004 . (2) The bigger the shear modulus is, the larger the equivalent plastic strain amplitude is. When the initial value of Shear modulus is $9.5 \mathrm{GPa}$, the maximum equivalent plastic strain is only $1.088 \times 10^{-4}$. As the gradually increasing of shear modulus, the equivalent plastic strain amplitude is also on the increase. (3) From figure 1(a) to (f) can be seen, along with the shear modulus increases constantly, equivalent distribution of plastic zone also has obvious regular variety: It can be observed from figure 1(a) to figure 1(f), with the increase of the shear modulus, the shape of plastic zone has obvious changes. When the shear modulus is small, the plastic zone is flat to slope surface and slope toe. When the shear modulus increases gradually, plastic zone develops from the toe to the slope inner; the whole plastic zone is an isosceles triangle shape.

\section{Unit weight influence on the stability of rock mass}

Increasing the unit weight of rock mass, gravity of slope gravity also will increases. In the finite element calculation, the gravity of slope is its vertical load by the outside world. The natural densities of rock mass slope are also difficult because of its different types of internal constituents into rock mass. At this point, the shear modulus value $\mathrm{G}$ fixed $12 \mathrm{GPa}$. To the different values of unit weight, the safety factors are calculated such as table 3 .

Table 2 Unit weight vs. Safety factors

\begin{tabular}{llllllll}
\hline $\begin{array}{l}\text { Unit Weight } \\
{\left[\mathrm{KN} / \mathrm{m}^{3}\right]}\end{array}$ & 20 & 21 & 22 & 23 & 24 & 25 & 26 \\
\hline Safety Factor & 1.106 & 1.103 & 1.069 & 1.069 & 1.056 & 1.056 & 1.014 \\
\hline
\end{tabular}




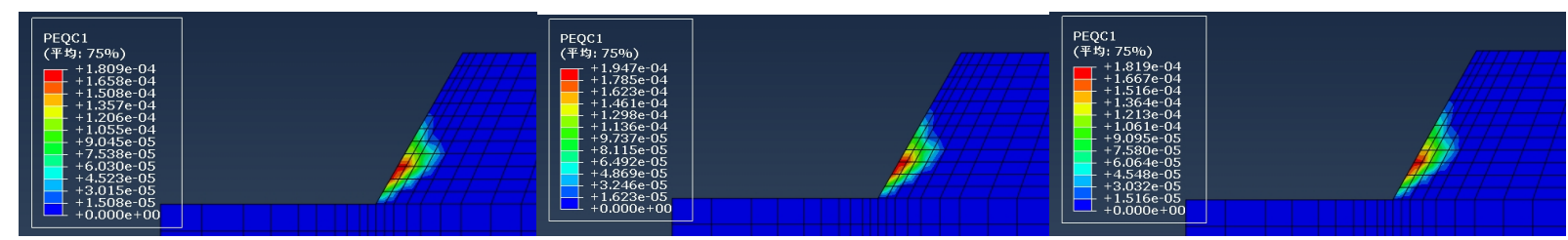

(a) $\mathrm{G}=20 \mathrm{KN} / \mathrm{m}^{3}$

(b) $\mathrm{G}=21 \mathrm{KN} / \mathrm{m}^{3}$

(C) $\mathrm{G}=22 \mathrm{KN} / \mathrm{m}^{3}$

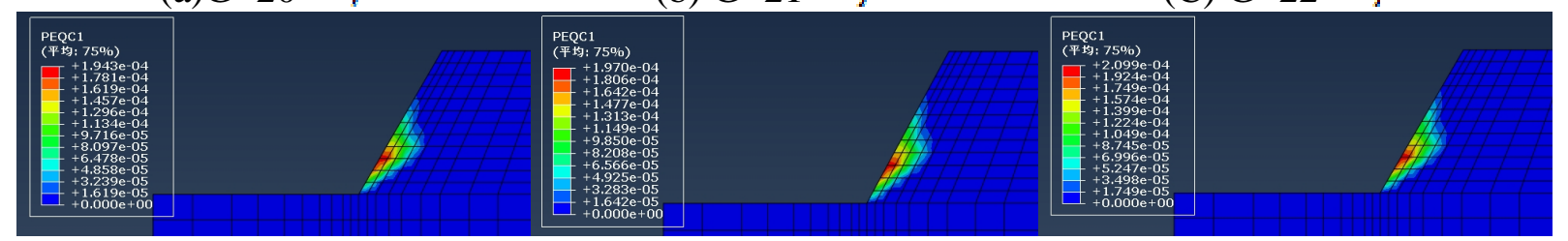
(d) $\mathrm{G}=23 \mathrm{KN} / \mathrm{m}^{3}$
(e) $\mathrm{G}=24 \mathrm{KN} / \mathrm{m}^{3}$
(f) $\mathrm{G}=25 \mathrm{KN} / \mathrm{m}^{3}$

Fig.2 Equivalent plastic strain contours of unit weight

Conclusion: (1) Can be found from table 2, with the increase of unit weight, the safety factor of slope is decreasing gradually. But reduction of range is small: With the unit weight increased from $20 \mathrm{KN} / \mathrm{m}^{3}$ to $26 \mathrm{KN} / \mathrm{m}^{3}$, the safety factor decreases from 1.106 to 1.106 . Of $22 \mathrm{KN} / \mathrm{m}^{3}$ and $23 \mathrm{KN} / \mathrm{m}^{3} ; 24 \mathrm{KN} / \mathrm{m}^{3}$ and $25 \mathrm{KN} / \mathrm{m}^{3}$ two sets data of unit weight, the safety factors are exactly same after the decimal point three significant figures, the results were 1.069 and 1.056 respectively. (2) From the figure 2(a) to figure 2(f) can be observed: With the increase of unit weight, plastic zone is developed to the inside of the slope and crest of slope slowly. The whole shape of it has no obvious change. And the expanding velocity of plastic zone area is small. In this example, with $1 \mathrm{KN} / \mathrm{m}^{3}$ gain increases of unit weight, increase range of plastic zone area is about $60 \mathrm{~m}^{2}$ to $150 \mathrm{~m}^{2}$, accounted for $0.18 \%$ to $0.45 \%$ of the whole slope area. And average value of the equivalent plastic strain in extensive plastic area is small, about $10^{-5}$ grade.

\section{The impact of the joint plane angle to the stability}

There are usually one or over one set joint planes in the rock slope. These joint angle and intensity play an important role on the slope stability. In this example, the author assumes that there are two sets of joint perpendicular to the cross section and intersecting in the slope.

Table 3 Joint planes angles vs. Safety factors and Equivalent Strain amplitude

\begin{tabular}{lllll}
\hline$\alpha$ & $20^{\circ}$ & $30^{\circ}$ & $40^{\circ}$ & $50^{\circ}$ \\
\hline Safety Factors & 1.035 & 1.012 & 1.002 & 0.811 \\
\hline $\begin{array}{l}\text { Equivalent Strain } \\
\text { Amplitude[10 }\end{array}$ & 1.206 & 1.296 & 1.466 & 2.097 \\
\hline
\end{tabular}

The change of safety factors and equivalent strain amplitude along $\alpha$ is shown as table 3. We can draw the conclusion: (1) The safety factor of slope is decreased with increase of the joint plane angle $\alpha$. The safety factor of slope is reduced from 1.035 with $\alpha-20^{\circ}$ to 0.811 with $\alpha-50^{\circ}$. (2) The equivalent plastic strain amplitudes grow with joint angle $\alpha$ increases in the two groups of the joint planes. When the joint plane angles $\alpha$ increased from $20^{\circ}$ to $50^{\circ}$, the equivalent plastic strain amplitude increases from $1.206 \times 10^{-4}$ to $2.097 \times 10^{-4}$. (3) With the increase of joint plane angle $\alpha$, plastic strain zone is concentrated downward and developed slowly; the area of the plastic strain areas at the slope crest has obviously decrease that lead to considerable changes of the plastic strain areas' shape and decrease of area of the plastic strain areas.

\section{Conclusion}

The shear modulus of rock mass, unit weight, and the angle of joint plane are very important data to measure the slope stability, they have important influence on the safety of slope and the failure pattern. Through the analysis of above examples: 
(1) When the shear modulus increases: the slope safety factor is improved; plastic strain zone in slope toe decreases until it disappeared, plastic strain zone is developed to slope internal, the plastic strain areas there are obvious changes in shape.

(2) When the natural unit weight of slope increases: the slope safety factors are decreased; plastic strain zone slowly developed to slope crest and slope internal, the plastic strain area shape and area have no obvious change.

(3) when the joint plane angle of slope internal increases: the slope safety factors decrease; plastic strain area at slope crest decreases, and plastic strain area is developed to the slope internal, the whole shape of the plastic area has obvious change and area is increased significantly.

\section{Reference}

[1] Zeng Jiquan, Yang Zongcai. Dip effect of structural plane on shearing strength parameters of rock mass[J]. Chinese Journal of Rock Mechanics and Engineering, 2004， （23） 3418 - 3425.

[2]Harrison JP, Hudson JA. Engineering rock mechanics[M].Oxford: Pergamon,2000:114 - 120.

[3]Zhang Xiaoyong,Dai Ziqiang.Stability analysis on jointed rock slope using ABAQUS program[J]. Journal of Guangxi University; Nat Sci Ed, 2009, 34 ( 4 ):444-450.

[4] Zhang Xuekun,Cui Wei,Lan Qi, Sun Bo. Numerical Research of Rock Mass Mechanics Properties under the Influence of Scale Effects and Anisotropy [J]. Journal of Shenyang Jianzhu University (Natural Science),2013,23(1):16-22.

[5] Wu Shunchuan,Jin Aibing,Gao Yongtao. Slope stability analysis by strength reduction method based on ubiquitous-joint model [J]. Rock and Soil Mechanics,2006,27(4):537-542.

[6] Carpinteri A, Puzzi S. A fractal approach to indentation size effect [J]. Engineering Fracture Mechanics, 2006, 73(15):2110 - 2122.

[7] Tang C A, Wang S H, Tham L G, et al. Numericalapproach to strength characterization of rock underdirect uniaxial tension [C] / /Second International Symposium on New Development in Rock Mechanics and Rock Engineering, New Jersey: Rinton Press, 2002.

[8] Zheng Wentang,Xu Weiya,Ning Yu,et al.Scale effect and anisotropy of deformation modulus of closely jointed basaltic mass [J].Journal of Engineering Geology,2010,18(4): 0559-0565.

[9] Zhang Shangbin,Zheng Yingren,Zhang Yufang. Study on slope failure criterion in strength reduction finite element method[J]. Rock and Soil Mechanics,2005,26(2):332-336.

[10] Zheng hong,Lichunguang,Li Zhuofen,etc. Finite element method for solving the factor of safety[J]. Chinese Journal of Geotechnical Engineering,2002,24(5):626-628. 